\title{
Current Research Issues in Production Economics Introduction
}

This Special Issue includes a selection of papers originally presented and discussed at the Twentieth International Working Seminar on Production Economics, Innsbruck, February 19-23, 2018, and subsequently extended and improved.

Production Economics was established in the1970s as an academic discipline focusing on scientific topics treating the interface between engineering, management, and economics with a special emphasis on financial consequences of decisions in the production domain. The subject is interdisciplinary in nature and it therefore contains a wide range of topics. The Working Seminar included sessions such as supply chain management, innovation management, general production economics, productivity and performance analysis, service management, risk management in production, inventory control, scheduling, forecasting, simulation applications, green and reverse logistics, manufacturing strategy, production planning and control, investment and financial planning. The 20th Working Seminar had 183 participants from 29 countries and provided an excellent opportunity for the participants to broaden study horizons, exchange research ideas and promote development of the unique production economics community.

The Seminar was opened with a Welcoming Address by the Vice Rector for Research, University of Innsbruck, Professor Dr Ulrike Tanzer, followed by a Keynote Lecture "Text Mining for Data Collection in Production Economics Research" by Professor Ou Tang, Linköping Institute of Technology.

As members of this stimulating community we would like to thank the Organisation Committee of the Working Seminar:

Robert W. Grubbström, Linköping Institute of Technology

Hans H. Hinterhuber, Universität Innsbruck

Janerik Lundquist, Linköping Institute of Technology

Andrea Mayr, Universität Innsbruck

the members of the Programme Committee

Marija Bogataj, University of Ljubljana

Dilay Çelebi, Istanbul Technical University

Attila Chikán, Corvinus University, Budapest

Huiping Ding, Beijing Jiaotong University

Alexandre Dolgui, IMT Atlantique, Nantes

Günter Fandel, Fern-Universität Hagen

Ludo F. Gelders, Katholieke Universiteit, Leuven

Richard F. Hartl, Universität Wien

Giovanna Lo Nigro, Università di Palermo

Hiroaki Matsukawa, Keio University, Yokohama

Stefan Minner, Technische Universität München

Christopher O'Brien, University of Nottingham

Costas Pappis, University of Piraeus

Lorenzo Peccati, Università Commerciale Luigi Bocconi, Milan

John Rowcroft, University of New Brunswick

Ruud H. Teunter, University of Groningen

Markku Tuominen, Lappeenranta University of Technology 
Stephan M. Wagner, Eidgenössige Technische Hochschule, Zürich

D. Clay Whybark, University of North Carolina, Chapel Hill

and the Chairmen of the sessions and the Discussants who contributed to the Twentieth International Working Seminars on Production Economics.

As Guest Editors, we gratefully acknowledge the contribution from all of the authors and the referees that generously offered their precious time and expertise to this publication.

Among the 140 papers presented in the Working Seminar, 87 papers were submitted to this special issue and finally 25 papers were accepted. All selected papers have been through a thorough refereeing process entailing the authors to revise their manuscript several times and improve it significantly.

This Special Issue covers a rich mix of topics related to Production Economics as Performance Measurement, Production Planning and Control, Supply Chain Management and Supply Chain Strategy, Game theory applications, Servitization, Lean production. The accepted papers are listed below.

The twenty-first Working Seminar will be held in Innsbruck February 24-28, 2020.

Newark, Palermo, London, August 2019

Layek Abdel-Malek

New Jersey Institute of Technology

University Heights

Department of Mechanical \& Industrial Engineering

Newark, New Jersey US

E-mail address: layek.abdel-malek@njit.edu

Giovanna Lo Nigro

Department of Engineering,

University of Palermo,

Palermo, Italy

E-mail address: giovanna.lonigro@unipa.it

\section{Li Zhou}

Business School, Systems Management and Strategy Department

University of Greenwich

London, UK

E-mail address: li.zhou@greenwich.ac.uk

\section{References}

Oussama Ben-Ammar, Belgacem Bettayeb, Alexandre Dolgui, Optimization of multi-period supply planning under stochastic lead times and a dynamic demand, This issue

Violetta G. Cannas, Jonathan Gosling, Margherita Pero, Tommaso Rossi, Engineering and production decoupling configurations: An empirical study in the machinery industry, This issue 
Kuen-Suan Chen, Ching-Hsin Wang, Kim-Hua Tan, Developing a Fuzzy Green Supplier Selection Model Using Six Sigma Quality Indices, This issue

Huiping Ding, Xiangbo Chen, Kuanhai Lin, Yunbing Wei, Collaborative Mechanism of Project Profit Allotment in Petroleum Engineering Service Chain with Customized Integration, This issue

Xiaoyu Gua, Li Zhou, Petros leromonachou, An Imperfect Information Game in Subsidising the Electric Vehicle Supply Chain, This issue

Robert W. Grubbström, The Dependence of the Incremental Risk Rate of Interest on Absolute Risk Aversion - Applying the Laplace Transform to Risk Preference Evaluation, This issue

Peng He, Yong He, Henry Xu, Channel Structure and Pricing in a Dual-Channel ClosedLoop Supply Chain with Government Subsidy, This issue

Jiangtao Hong, Yi Liao, Yibin Zhang, Zhefu Yu, The effect of supply chain quality management practices and capabilities on operational and innovation performance:

Evidence from Chinese manufacturers, This issue

Qinghua Huang, Shilei Yang, Victor Shi, Yibin Zhang, Strategic Decentralization under Sequential Channel Structure and Quality Choices, This issue

Malin Johansson, Jan Olhager, Comparing offshoring and backshoring: The role of manufacturing site location factors and their impact on post-relocation performance, This issue

Bart L. MacCarthy, Lina Zhang, Luc Muyldermans, Best Performance Frontiers for BuyOnline-Pickup-in-Store Order Fulfilment, This issue

B. Marchi, S. Zanoni, L.E. Zavanella, M. Y. Jaber, Supply chain models with greenhouse gases emissions, energy usage, imperfect process under different coordination decisions, This issue

Giovanni F. Massari, Ilaria Giannoccaro, Giuseppe Carbone, Are distrust relationships beneficial for group performance? The influence of the scope of distrust on the emergence of collective intelligence, This issue

Andreas Myrelid, Jan Olhager, Hybrid manufacturing accounting in mixed process environments: A methodology and a case study, This issue

Grigory Pishchulov, Alexander Trautrims, Thomas Chesney, Stefan Gold, Leila Schwab, The Voting Analytic Hierarchy Process Revisited: A Revised Method with Application to Sustainable Supplier Selection, This issue

Dinh Anh Phan, Thi Le Hoa Vo, Anh Ngoc Lai, Thi Lan Anh Nguyen, Coordinating contracts for VMI systems under manufacturer-CSR and retailer-marketing efforts, This issue

Patricia Rogetzer, Lena Silbermayr, Werner Jammernegg, Sustainable Sourcing including Capacity Reservation for Recycled Materials: A Newsvendor Framework with Price and Demand Correlations, This issue

Paolo Roma, Umberto Panniello, Giovanna Lo Nigro, Sharing economy and incumbents' pricing strategy: The impact of Airbnb on the hospitality industry, This issue

Levente Szász, Béla-Gergely Rácz, Maike Scherrer, Patricia Deflorin, Disseminative capabilities and manufacturing plant roles in the knowledge network of MNCs, This issue

Sarah Van der Auweraer, Robert Boute, Forecasting Spare Part Demand using Service Maintenance Information, This issue

James M. Wakiru, Liliane Pintelon, Peter N. Muchiri, Peter K. Chemweno, A simulationbased optimization approach evaluating maintenance and spare parts demand interaction effects, This issue

Yingli Wang, Meita Singgih, Jingyao Wang, Mihaela Rit, Making sense of blockchain technology: How will it transform supply chains? , This issue 
Matthias Gerhard Wichmann, Christoph Johannes, Thomas Stefan Spengler, Energyoriented lotsizing and scheduling considering energy storages, This issue

Yi Zhang, Guowei Hua, T.C.E. Cheng, Juliang Zhang, Vicenç Fernandez, Risk pooling through physical probabilistic selling, This issue

Xiao-Xue Zheng, Zhi Liu, Kevin W. Li, Jun Huang, Ji Chen, Cooperative Game Approaches to Coordinating a Three-echelon Closed-loop Supply Chain with Fairness Concerns, This issue 